\title{
Planejamento, desenvolvimento e implantação do Programa Pró- Multiplicar da CAPES na UFMG: metodologia aplicada
}

Beatriz Valadares Cendón

\begin{abstract}
Professora Titular daEscola de Ciência da Informação Departamento de Organização e Tratamento da Informação Universidade Federal de Minas Gerais
\end{abstract}

Maria Elizabeth de Oliveira Costa

\begin{abstract}
Mestre em Tecnologia e Gestão em Educação a Distância.Diretora do Sistema de Bibliotecas Universidade Federal de Minas Gerais
\end{abstract}

Em 2010, a Universidade Federal de Minas Gerais (UFMG) aderiu ao programa Pró-Multiplicar da CAPES. O Programa visa a capacitar alunos bolsistas de doutorado/ mestrado da CAPES em instituições credenciadas pelo Portal, para atuarem como monitores e multiplicadores na divulgação e instrução sobre o uso do Portal de Periódicos, junto aos seus colegas de graduação e pós-graduação. Após o encerramento e avaliação das atividades do PróMultiplicar na UFMG, foram treinados, pelos instrutores da CAPES e das editoras presentes no Portal, 48 alunos multiplicadores e 17 bibliotecários, que deram suporte ao Programa. Por meio de uma metodologia criada e aplicada pela Coordenação do Programa na instituição, 43 alunos multiplicadores, por sua vez, realizaram 72 treinamentos para 293 alunos de graduação e pós-graduação. Considera-se, assim, ter alcançado, com sucesso, os objetivos pretendidos. Este artigo visa a compartilhar a metodologia desenvolvida, a experiência obtida na implantação do Programa na instituição e os demais resultados preliminares obtidos nos treinamento do programa Pró-Multiplicar da CAPES na UFMG. Com base nesta experiência, o artigo também oferece sugestões para o fortalecimento do Programa Pró-Multiplicar.

Palavras-chave: Programa Pró-Multiplicar CAPES; Treinamento; UFMG. 


\section{Planning, development and implantacion of the Pro Mutiply Program the CAPES, in UFMG: applied methodology}

In 2010, the Federal University of Minas Gerais, Brazil (UFMG) started participating in the CAPES Pró-Multiplicar Program. This program aims at preparing graduate students to be instructors and teach other students and faculty members about the use of the CAPES Portal of Scientific Information, a major digital library in Brazil. The evaluation of the results of the program showed that 43 students and 17 librarians were trained by the database vendors. These students, in turn, performed 72 training sections and taught 293 graduate and under-graduate students. These results reveal that the objectives of the program were successfully attained. This article shares the methodology developed for the process, the experience in the implementation of the program and results obtained. Base on the experience, the article also offers suggestions for the strengthening of the program.

Key words: CAPES Pró-Multiplicar Programe; Training; Databases.

Recebido em 20.05.2012 aceito em 09.04.2013

\section{Introdução}

A Coordenadoria de Aperfeiçoamento de Pessoal de Nível Superior (CAPES), no ano de 1999, buscando ampliar o acesso à informação científica internacional para as bibliotecas e instituições de ensino e pesquisa brasileiras, deu os primeiros encaminhamentos a iniciativas para o oferecimento online destas informações. A entrada, nesta mesma época, no mercado brasileiro, de grandes editoras científicas internacionais, oferecendo seus acervos em forma digital, favoreceu a criação de um grande consórcio entre a CAPES e as instituições de ensino e pesquisa no Brasil, dando origem ao Portal de Periódicos da CAPES. Este, que veio a se tornar a principal fonte de informação científica e um dos maiores empreendimentos realizados neste campo no Brasil, permitiu à comunidade acadêmica brasileira acesso online, gratuito e atualizado ao melhor da produção científica e tecnológica produzida no mundo (KURAMOTO, 2008). É inquestionável a sua importância para a ciência brasileira e para os avanços científicos obtidos pelo país. 
Lançado em 2000, o Portal conta, em setembro de 2011,

[...] com um acervo de cerca de 30 mil títulos com texto completo, 130 bases referenciais, dez bases dedicadas exclusivamente a patentes, além de livros, enciclopédias e obras de referência, normas técnicas, estatísticas e conteúdo audiovisual. (CAPES, 2011, on-line).

Com o objetivo de aprimorar o atendimento à sua comunidade alvo, o Portal está em constante modificação, tanto em relação ao seu acervo, que vem sendo progressivamente ampliado, quanto em relação à sua interface. Essas modificações tornam mais importantes e necessárias as atividades de treinamento, o que foi uma das motivações para 0 lançamento, pela CAPES, de um programa denominado Programa PróMultiplicar, que tem por foco atividades de capacitação da comunidade acadêmica no uso do Portal.

De acordo com a Portaria no 144, de 20 de outubro de 2009, o Programa Pró-Multiplicar visa a capacitar alunos bolsistas de doutorado/mestrado da CAPES em instituições credenciadas pelo Portal para atuarem como monitores e multiplicadores na divulgação e instrução sobre o uso do Portal de Periódicos da CAPES, junto aos seus colegas de graduação e pós-graduação. Segundo a CAPES:

A ampliação das bases [de dados] do Portal de Periódicos justifica a constante atualização e treinamento das instituições participantes e a participação dos bolsistas trará um elemento novo ao treinamento que se dará de colega para colega, destacando os conteúdos de interesse do pesquisador. (BRASIL, 2009).

O Programa vem sendo implantado nas universidades do país, nos últimos dois anos, tendo a UFMG aderido ao programa em 2010. Ao fim deste ano, após o encerramento e avaliação das atividades do Programa na UFMG, considera-se ter-se alcançado, com sucesso, os objetivos pretendidos. Foram treinados, pelos instrutores das CAPES e das editoras presentes no Portal, 43 alunos multiplicadores e 17 bibliotecários, que deram suporte ao Programa. Após o treinamento pelos instrutores da CAPES, os alunos multiplicadores, por sua vez, realizaram 72 treinamentos para 293 alunos de graduação e pós-graduação. A metodologia adotada para a multiplicação mostrou-se também eficaz, visto que, apesar dos alunos multiplicadores não terem formação específica na área de ciência da informação ou em biblioteconomia, 98\% dos alunos por eles treinados os consideraram excelentes ou bons como instrutores; $97 \%$ consideram o conteúdo recebido excelente ou bom; e $76 \%$ afirmaram serem capazes de reproduzir o treinamento recebido. 
Este artigo visa a compartilhar a metodologia desenvolvida e a experiência obtida na implantação do Programa Pró-Multiplicar, bem como os resultados preliminares obtidos nos treinamentos e sugestões para fortalecimento do Programa, advindas desta experiência e do feedback recebido.

\section{Programa Pró-Multiplicar da CAPES}

O Pró-multiplicar propõe o treinamento de bolsistas da CAPES para atuar na multiplicação do conhecimento recebido sobre o uso das bases de dados do Portal em suas universidades.

De acordo com a Portaria que institui o Projeto de Formação de Multiplicadores do Portal de Periódicos da CAPES, o Pró-Multiplicar tem os seguintes objetivos específicos (BRASIL, 2009):

a)Incentivar os alunos e pesquisadores da instituição a utilizarem os recursos do Portal na sua plenitude;

b)disseminar nas diversas áreas do conhecimento o uso do Portal nas instituições participantes;

c)incentivar a utilização dos diversos recursos eletrônicos disponíveis no portal de Periódicos e editores, facilitando assim o uso do mesmo pelos grupos de pesquisa nas instituições; e

d)possibilitar que as instituições possuam alunos e profissionais [com] "expertise" nos recursos do Portal de Periódicos nas diversas áreas do conhecimento com 0 compromisso de disseminar informação e promover treinamentos periódicos da comunidade acadêmica discente.

\section{Pró-Multiplicar na UFMG e a formação dos multiplicadores}

A Universidade Federal de Minas Gerais, por meio da Biblioteca Universitária, Coordenadora Técnica do Sistema de Bibliotecas (BUSIB/UFMG), já possuía, mesmo anteriormente ao Pró-Multiplicar, a prática de oferecimento de cursos e treinamentos sobre o uso do Portal para a comunidade acadêmica. Para melhor atender à comunidade, a Diretoria da BU-SB/UFMG criou, em dezembro de 2009, o Setor de Apoio aos Usuários do Portal de Periódicos da CAPES na UFMG, com o objetivo de cuidar do atendimento ao usuário, aumentar a visibilidade do Portal e oferecer, para usuários e bibliotecários, de forma contínua, programas de capacitação sobre a utilização dos recursos disponíveis. Além disso, o Setor também é responsável pelo atendimento personalizado de demandas de pesquisadores, professores, bibliotecários e alunos na instituição. Para auxiliar o Setor, um grupo de estudos, constituído de bibliotecários que atuam com o uso do Portal na UFMG, tem se especializado no uso das bases de dados por área do conhecimento, a fim de repassar esse conhecimento para a comunidade acadêmica da instituição. Além desses 
trabalhos, a BU tem lançado campanhas para incentivar a utilização do Portal. O Programa Pró-Multiplicar veio, portanto, ao encontro das iniciativas existentes, fortalecendo e ampliando as práticas já adotadas no sentido da capacitação do usuário e do aumento do uso do Portal.

O planejamento, desenvolvimento e implantação do Programa PróMultiplicar na UFMG, seguiu as orientações fornecidas na Portaria da CAPES no 144, de outubro de 2009, e contou com o trabalho em conjunto da BU-SB/UFMG, Escola Ciência da Informação, Pró-Reitoria de PósGraduação e Pesquisa, para que o programa atingisse os objetivos propostos.

Figura 1 - Interação do Programa Pró-Multiplicar CAPES na UFMG

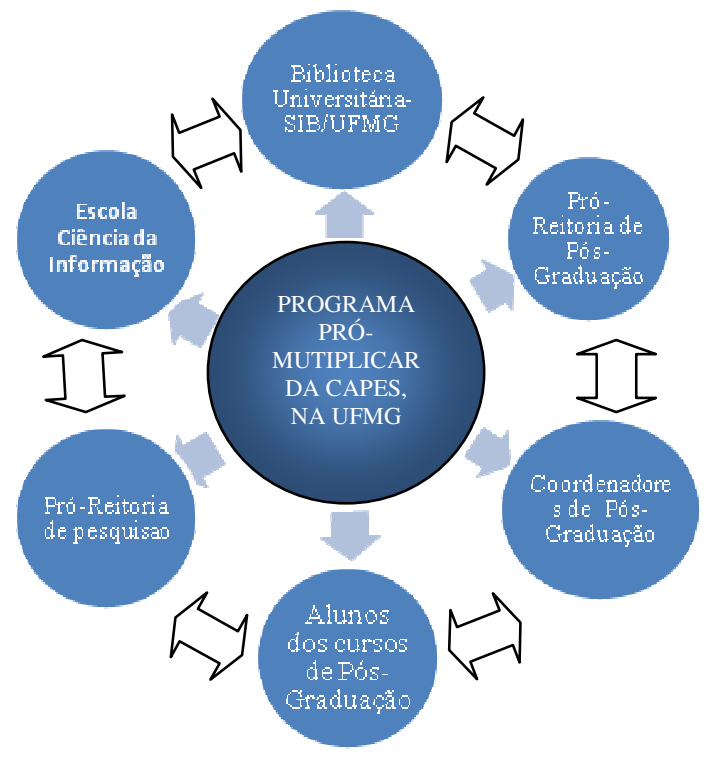

Fonte: Elaborada pelas autoras.

\subsection{Convocação e seleção dos bolsistas multiplicadores}

Para suscitar maior interesse e comprometimento, determinou-se que a carta inicial de convocação, dirigida a todos os programas de pósgraduação da instituição, seria emitida pelo Pró-Reitor de Pós-Graduação. Tal carta explicava o propósito do Programa Pró-Multiplicar e solicitava, a cada programa, a indicação de um aluno. Em uma segunda etapa, para aqueles programas que ainda não haviam indicado representantes, foi enviada nova carta.

Uma vez recebida a indicação dos alunos que representariam cada programa, eles foram convocados, através de mensagem emitida pela Coordenação do Pró-Multiplicar na UFMG, a se inscreverem no Programa através de um link no site da Biblioteca Universitária.

\subsection{Recebimento e gerenciamento das inscrições}

O formulário de inscrição, acessado pelo link http://www.bu.ufmg.br/promultiplicar/, solicitava os seguintes dados: 
Nome completo, Nacionalidade, CPF, Data de nascimento, Sexo, Número de matrícula, Telefone, E-mail, Nível do curso de Pós-Graduação, Curso, Programa, Unidade, Nome do professor que fez a indicação para participação no Programa, Área de formação, Área de interesse.

As inscrições foram gerenciadas pelos bibliotecários do Setor de Apoio aos Usuários do Portal de Periódicos da CAPES na Biblioteca Universitária, que mantiveram controle do número de inscritos, dos seus programas de origem, das áreas do conhecimento a que pertenciam e dos demais dados.

Ocorreu de alguns cursos não indicarem representantes e outros indicarem mais de um. Houve, também, alunos não bolsistas CAPES, que manifestaram interesse, além de bibliotecários de outras instituições no Estado, que desejavam participar do curso.

Após recebidos todos os pedidos de inscrição, verificou-se que as instalações disponíveis para as aulas possibilitavam atender a todas as demandas e não houve necessidade de se recusar quaisquer dos pedidos. A Tabela 1 mostra a distribuição dos inscritos:

Tabela 1 - Inscrições

\begin{tabular}{l|c|c}
\hline \multicolumn{1}{c|}{ Inscritos } & Participantes & $\begin{array}{c}\text { Inscritos } \\
\text { da UFMG }\end{array}$ \\
\hline \hline Alunos de pós-graduação da área de Ciências Biológicas & 17 & 43 \\
$\begin{array}{l}\text { Alunos de pós-graduação da área de Ciências Humanas e } \\
\text { Sociais Aplicadas }\end{array}$ & 18 & \\
$\begin{array}{l}\text { Alunos de pós-graduação da área de Ciências Exatas } \\
\text { Aluno de graduação da área de Ciências Humanas e Sociais }\end{array}$ & 5 & 5 \\
$\begin{array}{l}\text { Aplicadas } \\
\text { Bibliotecários do Sistema de Bibliotecas da UFMG }\end{array}$ & 17 & \\
Bibliotecários de outra instituição & 3 & \\
Coordenadores do Pró-Multiplicar na UFMG & $(2)$ & 65 \\
Total & 70 & \\
\hline
\end{tabular}

Fonte: Elaborada pelas autoras.

\subsection{Atividades de divulgação no Boletim da UFMG e no site da Biblioteca Universitária}

Como a realização dos treinamentos estava prevista para o início do mês de junho, paralelamente à convocação dos bolsistas, a partir do mês de abril, iniciou-se a publicação de matérias de divulgação no Boletim da UFMG. A primeira delas, em abril, informava à comunidade sobre o Programa Pró-Multiplicar, seus objetivos e forma de funcionamento.

No dia 08 de maio, um mês antes do início previsto para os treinamentos, a Biblioteca Universitária colocou, em seu site, o link, através do qual os participantes poderiam se inscrever. Nova matéria foi publicada, dando conhecimento à comunidade da abertura das inscrições 
e da forma como poderia ser feita. Outra matéria saiu no dia 7 de junho, data do início dos treinamentos.

\subsection{Programação dos treinamentos na etapa de formação de multiplicadores}

A programação para os treinamentos para a formação dos multiplicadores foi enviada à UFMG, pela CAPES, previamente, prevendo a data de sua realização, o seu conteúdo e propondo as salas de aula necessárias, conforme segue. O programa se dividia em duas partes.

$1^{a}$ Parte: apresentação do Portal de Periódicos e bases multidisciplinares

10 dia: treinamento inicial, contendo apresentação e orientações sobre o Programa Pró-Multiplicar e sobre o uso do Portal de Periódicos da CAPES a ser ministrado por técnico da CAPES. Apresentação das bases interdisciplinares Web of Science, Derwent Innovations Index, Scopus e do software End Notes Web (sala comum).

2a Parte: apresentação das bases de dados por área do conhecimento

A programação previa que os treinamentos sobre bases de dados específicas seriam ministrados pelos instrutores das editoras das bases de dados, simultaneamente, para três grandes áreas do conhecimento, no segundo e terceiro dias de treinamentos.

20 e $3^{0}$ dia Bases de dados das áreas de Ciências Exatas e da Terra, Agrárias e Engenharias (sala 1);

20 e 30 dia Bases de dados das áreas de Ciências da Saúde e Biológicas (sala 2); e

20 e 30 dia Bases de dados das áreas de Letras, Artes e Linguística, Ciências Humanas e Sociais Aplicadas (sala 3).

Como pode ser visto, a CAPES recomenda o uso de três salas, nas quais as aulas podem ocorrer, simultaneamente. De acordo com 0 cronograma da CAPES, no primeiro dia, as aulas seriam conjuntas para todos os participantes de todas as áreas do conhecimento, exigindo um laboratório maior. Nos demais dias, os participantes se dividiriam por área do conhecimento, podendo, assim, utilizar-se laboratórios menores. 


\subsection{Definição da infraestrutura laboratorial e de Internet}

A definição do tamanho das salas de aulas necessárias dependia do número esperado de inscrições. Oferecendo a UFMG, na época, 68 Programas de pós-graduação, determinou-se, em reunião com a PróReitoria de Pós-Graduação, que cada curso poderia indicar um aluno representante para ser treinado como multiplicador, prevendo-se, então, inicialmente, em torno de 68 inscrições de alunos. Além dos alunos multiplicadores, alvo principal do Programa, determinou-se que seriam treinados, também, os bibliotecários da própria instituição, para suporte aos multiplicadores.

Com esta previsão inicial do número esperado de inscrições no programa, percebeu-se que seriam necessários para o treinamento quatro laboratórios. A Escola de Ciência da Informação (ECI) disponibilizou três destes (Laboratórios A, B e C). A Biblioteca Universitária (BU) disponibilizou a sua sala de treinamentos (Laboratório D). Todos contavam com aparelho de projeção multimídia e computadores conectados à Internet para alunos e professores.

Conforme informado pela CAPES, o instrutor de uma mesma editora poderia ministrar treinamentos para mais de uma área de conhecimento. $\mathrm{Na}$ escolha do local das salas de aula, considerou-se a necessidade de rápida locomoção dos instrutores que davam treinamentos em mais de uma sala. Para atender a esta necessidade, os laboratórios A, B e C estavam localizados no mesmo andar do prédio da ECI. O Quadro 1 mostra mais detalhes sobre a utilização de cada laboratório.

Quadro 1 - Laboratórios utilizados

\begin{tabular}{|c|c|c|c|c|}
\hline Laboratório & Local & $\begin{array}{c}\text { N. de } \\
\text { computa } \\
\text { dores }\end{array}$ & Utilização & Público \\
\hline \multirow[t]{3}{*}{ LABORATÓRIO A } & \multirow[t]{3}{*}{$\overline{\mathrm{ECl}}$} & \multirow[t]{3}{*}{40} & $\begin{array}{l}\text { Aula introdutória genérica para } \\
\text { todos os participantes (Dia 1) }\end{array}$ & $\begin{array}{l}\text { - Alunos } \\
\text { multiplicadores }\end{array}$ \\
\hline & & & $\begin{array}{l}\text { Aulas específicas para as áreas } \\
\text { de ciências biológicas e da saúde } \\
\text { (Dias } 2 \text { e 3) }\end{array}$ & \multirow{2}{*}{$\begin{array}{l}\text { - Alunos } \\
\text { multiplicadores } \\
\text { - Bibliotecários do } \\
\text { sistema }\end{array}$} \\
\hline & & & $\begin{array}{l}\text { Reunião da Coordenação com os } \\
\text { participantes (Dia 3) }\end{array}$ & \\
\hline LABORATÓRIO B & $\mathrm{ECl}$ & 28 & $\begin{array}{l}\text { Aulas específicas para as áreas } \\
\text { de letras, artes e linguística, } \\
\text { ciências humanas e sociais } \\
\text { aplicadas (Dias } 2 \text { e } 3 \text { ) }\end{array}$ & $\begin{array}{l}\text { - Alunos } \\
\text { multiplicadores } \\
\text { - Bibliotecários do } \\
\text { sistema }\end{array}$ \\
\hline LABORATÓRIO C & $\mathrm{ECl}$ & 24 & $\begin{array}{l}\text { Aulas específicas das áreas de } \\
\text { ciências exatas e da terra, } \\
\text { ciências agrárias e engenharia } \\
\text { (Dias } 2 \text { e } 3 \text { ) }\end{array}$ & $\begin{array}{l}\text { - Alunos } \\
\text { multiplicadores } \\
\text { - Bibliotecários do } \\
\text { sistema }\end{array}$ \\
\hline LABORATÓRIO D & BU & 24 & $\begin{array}{l}\text { Aula introdutória para todos os } \\
\text { participantes (Dia 1) }\end{array}$ & $\begin{array}{l}\text { - Bibliotecários do } \\
\text { sistema }\end{array}$ \\
\hline
\end{tabular}

Fonte: Elaborada pelas autoras. 


\subsection{Recursos Humanos na instituição para apoio ao programa}

Para as diversas etapas, envolvendo desde a divulgação até as etapas de treinamento, o Programa contou com o apoio de um técnico de informática disponível para o programa, um fotógrafo, uma jornalista, um operador de audiovisual, para a gravação e transmissão dos treinamentos, um assistente em administração e bibliotecários do SB/UFMG. Com o apoio destes, foi criado e confeccionado, na instituição, material impresso usado na comunicação e divulgação, tais como cartazes, banners e folders com o cronograma e horários de cada treinamento para os alunos do Programa Pró-multiplicar. Na primeira e segunda etapa de treinamentos, realizadas nos recintos da ECI e BU, a equipe de suporte de informática foi mobilizada e a sua atuação foi essencial para a satisfação de alunos e instrutores. Na segunda etapa de treinamento e no apoio aos alunos multiplicadores na preparação das aulas, foi essencial o envolvimento dos bibliotecários do Sistema.

\subsection{Outras providências relativas à infraestrutura de apoio}

Além dos itens acima, os seguintes preparativos foram realizados pela BU e ECI para garantir o bom funcionamento do programa:

Nos meses anteriores ao evento:

a)setores competentes da BU foram acionados para a confecção do site do programa, com link para inscrição e para confecção de pôsteres, folders e material de divulgação;

b)setores competentes da UFMG foram acionados para providenciar a transmissão das aulas via Internet;

c)o Setor de Serviços Gerais da ECI foi informado sobre o evento e sobre a colaboração que seria requerida para sinalização da Escola, orientação dos participantes e organização dos recintos utilizados;

d)o Laboratório de Tecnologia da Informação foi informado, com a antecedência devida, sobre os requisitos da CAPES no que se refere à tecnologia de apoio necessária para as aulas, tais como a necessidade de instalação prévia de software nos computadores. Foi, também, solicitada ao LTI, a disponibilização de suporte técnico imediato, em caso de ocorrerem problemas com algum dos computadores durante as aulas; e

e)a Coordenadoria de Assuntos Comunitários da UFMG foi acionada para a gravação das aulas nos três laboratórios. Estas gravações foram posteriormente colocadas em DVDs, os quais ficaram à disposição dos alunos multiplicadores. 
Na semana anterior ao evento:

uma mensagem foi enviada para toda a comunidade da ECI, dando ciência a alunos, professores e funcionários sobre 0 evento que estaria ocorrendo nos recintos da Escola e pedindo a colaboração na orientação dos participantes externos que estariam circulando nos recintos da Escola, caso fossem abordados.

Durante o evento:

a)pôsteres com a programação do evento e indicação da localização de cada aula foram colocados próximos às salas de aula;

b) um folder, contendo a programação do evento e localização das salas, foi preparado distribuído entre os participantes; e

c)uma lista de presença para assinaturas foi disponibilizada para cada sala de aula e cada turno.

\section{Metodologia do processo de multiplicação}

A Coordenação do Pró-Multiplicar na UFMG, norteada pela programação do treinamento e pelo conteúdo ministrado pela CAPES e pelas editoras e, ainda, pela lista de alunos e bibliotecários participantes, elaborou um calendário de aulas para cada uma das três grandes áreas de conhecimento. Este calendário previa aulas diárias, de agosto até dezembro de 2010, designava o multiplicador responsável por cada conteúdo, bem como as datas em que se dariam os treinamentos ministrados por eles, além do horário e duração das aulas. A programação definia, ainda, para cada base de dados, um bibliotecário para dar suporte aos alunos. Para a programação, seguiu-se, também, a orientação da CAPES na Portaria N. ${ }^{0}$ 144, que diz, em seu Capítulo V, Artigo 10, que cada multiplicador deverá realizar, no mínimo, um treinamento por ano e treinar, no mínimo, dois outros alunos (BRASIL, 2009).

Para que a BU pudesse manter o controle da realização dos treinamentos e dos alunos treinados, definiu-se que seria utilizada para essas aulas a sala de treinamentos da Biblioteca Universitária. Como já dito, as inscrições e controle de presença nas aulas foram gerenciados pela BU que também ficou responsável pela comunicação dos treinamentos realizados, para emissão de certificados.

$\mathrm{Na}$ definição do conteúdo a ser ministrado pelos multiplicadores, considerou-se o fato de que eles não tinham formação na área de biblioteconomia e ciência da informação e que haviam recebido, em apenas três dias, 24 horas de treinamento, com uma grande sobrecarga cognitiva. Para garantir a possibilidade de domínio pelo aluno multiplicador do conteúdo a ele designado e, consequentemente, a qualidade dos treinamentos que eles realizariam, utilizou-se, como estratégia, a definição de uma base de dados (ou um pequeno conjunto 
caso elas fossem muito simples ou semelhantes), a qual o multiplicador deveria estudar, dando-Ihe condições, assim, de conhecê-la a fundo e sentir-se seguro para ministrar o treinamento.

Também com a mesma preocupação de apoiar os multiplicadores na preparação das suas aulas, com a autorização da CAPES e das editoras, as aulas ministradas pelos instrutores foram filmadas e posteriormente editadas e gravadas em DVDs, que foram disponibilizados para os multiplicadores na Biblioteca Universitária. Após consulta aos representantes das editoras, foi dada ao multiplicador permissão para fazer cópias desses DVDs para seu estudo. O multiplicador foi informado sobre a existência de outros materiais instrucionais disponíveis no site do Portal e da possibilidade de contato direto com os representantes das editoras, em caso de dúvidas. Em cada unidade da UFMG, foi designado um bibliotecário, com a função de dar suporte aos alunos na preparação das aulas e aprovar o material didático a ser utilizado.

Preferencialmente, procurou-se alocar bases da área de conhecimento a qual o aluno pertencia, o que nem sempre foi possível, já que havia mais alunos da área de ciências da saúde e biológicas do que bases de dados a serem ensinadas; enquanto na área de ciências exatas e da terra, ciências agrárias e engenharias havia um número de multiplicadores menor que o demandado. Em alguns casos, foi necessária a atuação dos bibliotecários como multiplicadores.

Os multiplicadores que desejassem realizar outros treinamentos específicos para as suas áreas, unidades e programas de pós-graduação, além dos treinamentos previstos na programação planejada pela Coordenação do Pró-Multiplicar na UFMG, foram instruídos a entrar em contato com o Setor de Apoio aos Usuários do Portal Periódicos da CAPES, na Biblioteca Universitária, e requisitar o acompanhamento de um bibliotecário para as suas aulas.

No último dia da primeira etapa de treinamento (treinamento dos alunos multiplicadores), todos os participantes do treinamento foram reunidos para os esclarecimentos iniciais, feito pelas coordenadoras do Pró-Multiplicar na UFMG, de como se daria o processo de multiplicação. Nesta reunião, dúvidas foram esclarecidas, bem como sugestões foram apresentadas pelos participantes, havendo, também, oportunidade para aqueles que não se sentiram à vontade com o conteúdo a eles designados solicitarem alterações.

Buscou-se ajustar a programação para atender às solicitações e, após as revisões, foi enviada mensagem a todos os multiplicadores, informando o calendário definitivo de treinamento.

Pediu-se que, para cada um dos dois treinamentos que ministraria, - multiplicador trouxesse dois alunos interessados. Assim, caso não houvesse outras inscrições, a aula seria ministrada apenas para estes alunos.

A programação com a lista das bases de dados e dias das aulas foi divulgada para a comunidade da UFMG no site da Biblioteca Universitária e, também, via e-mail, com links para o local das inscrições. 


\section{Treinamentos}

O evento se deu em duas etapas, conforme o programa da CAPES descrito no item 3.4. Na primeira etapa, ocorrida nos dias 8 a 10 de junho de 2010, deu-se o treinamento dos multiplicadores e dos bibliotecários de apoio.

As aulas conjuntas para todos os alunos multiplicadores em treinamento foram realizadas na Escola de Ciência da Informação, que possuía o maior dos laboratórios, com 40 computadores. Apesar deste laboratório (A) comportar todos os inscritos (alunos e bibliotecários), se os alunos compartilhassem os computadores, para um melhor aproveitamento, esta aula inicial foi transmitida, via Internet, para o LABORATÓRIO $D$, na Biblioteca Universitária, no qual ficaram os bibliotecários e o LABORATÓRIO A apenas para os alunos.

Após esta aula inicial, que foi para todos os participantes, os bibliotecários se juntaram aos demais participantes na Escola de Ciência da Informação e o grupo de 43 inscritos foi distribuído entre as três salas de aulas, nas quais ocorreriam as aulas específicas para cada uma das três grandes áreas do conhecimento, definidas pela programação do evento, previamente enviada pela CAPES (ciências biológicas e da saúde / letras, artes e linguística, ciências humanas e sociais aplicadas / ciências exatas e da terra, ciências agrárias e engenharias), como mostra a Tabela 2.

Tabela 2 - Alocação das salas para aulas por área específica do conhecimento

\begin{tabular}{lccc}
\hline Área do conhecimento & Laboratório & $\begin{array}{l}\text { No de } \\
\text { computadores }\end{array}$ & $\begin{array}{l}\text { No de alunos } \\
\text { pós- } \\
\text { graduação }\end{array}$ \\
\hline Ciências biológicas e da saúde & $\mathrm{A}$ & 40 & 17 \\
$\begin{array}{l}\text { Letras, artes e linguística, ciências } \\
\text { humanas e ciências sociais aplicadas }\end{array}$ & $\mathrm{B}$ & 28 & 18 \\
$\begin{array}{l}\text { Ciências exatas e da terra, ciências } \\
\text { agrárias e engenharias }\end{array}$ & $\mathrm{C}$ & 24 & 8 \\
\hline Fonte: Elaborada pelas autoras. & & &
\end{tabular}

Todos os treinamentos foram também transmitidos abertamente via internet e através do link http://www.bu.ufmg.br/pro-multiplicar, que foi anunciado e disponibilizado na página da BU e ECI.

$\mathrm{Na}$ segunda etapa, iniciada em 20 de agosto de 2010, foram ministrados treinamentos pelos alunos multiplicadores formados. A programação realizada resultou em um agendamento diário de aulas sobre as bases de dados do Portal durante os meses de agosto a dezembro, tornando a Biblioteca em um centro de treinamento

\section{Avaliação dos resultados}

No período de agosto a dezembro de 2010, o Programa treinou 293 usuários, sendo que cada multiplicador treinou entre 1 a 23 pessoas e 
ministrou entre 1 a 3 treinamentos, conforme mostra o Gráfico 1 e as Tabelas 3 e 4.

Gráfico 1 - Total de pessoas treinadas no Programa Pró-Multiplicar na UFMG

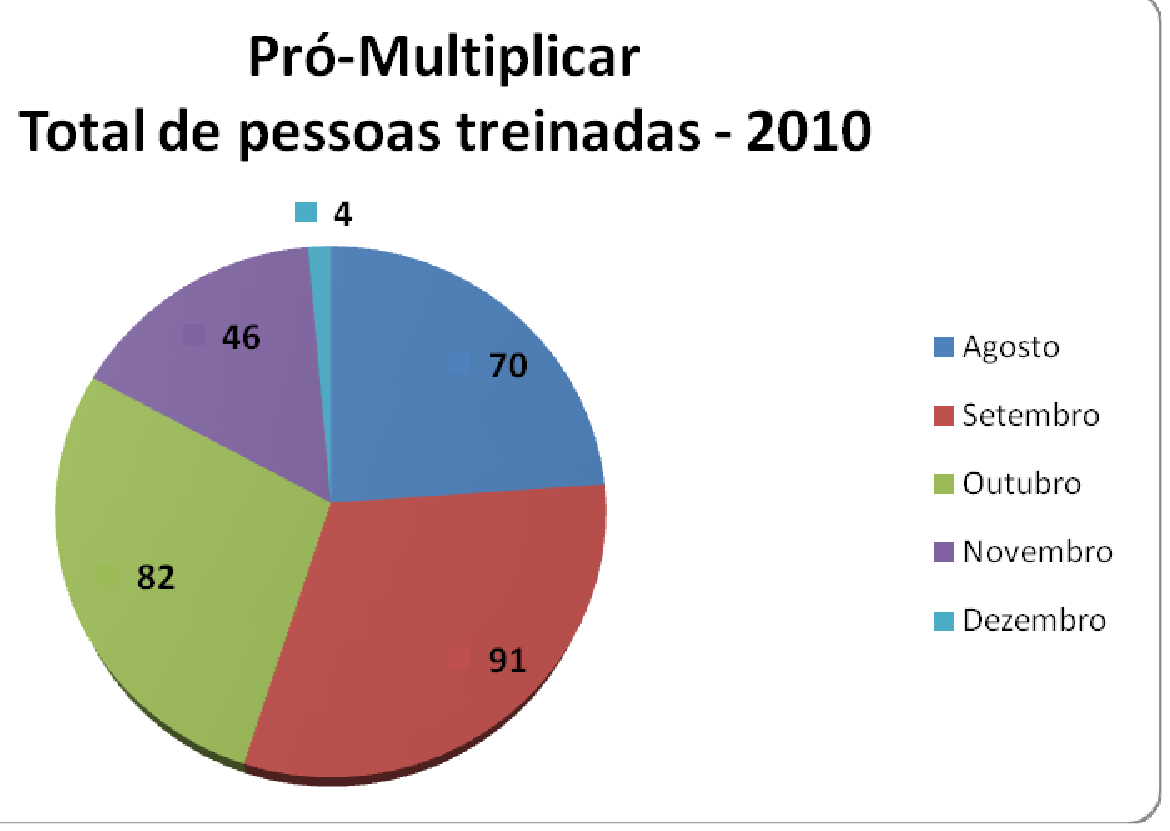

Fonte: Elaborado pelas autoras.

Tabela 3 - Relação entre multiplicadores e treinamentos ministrados

\begin{tabular}{cc}
\hline $\begin{array}{c}\text { N. de } \\
\text { Multiplicadores }\end{array}$ & $\begin{array}{c}\text { N. de } \\
\text { treinamentos }\end{array}$ \\
\hline 26 & 1 \\
20 & 2 \\
2 & 3 \\
\hline Fonte: Elaborada pelas autoras.
\end{tabular}

Tabela 4 - Relação entre multiplicadores e usuários treinados

\begin{tabular}{ccc}
\hline $\begin{array}{c}\text { N. de } \\
\text { Multiplicadores }\end{array}$ & $\begin{array}{c}\text { N. de Usuários } \\
\text { treinados }\end{array}$ & $\begin{array}{c}\text { N. de multiplicadores versus } \\
\text { N.usuários treinados }\end{array}$ \\
\hline \hline 6 & 1 & 6 \\
9 & 2 & 18 \\
5 & 3 & 15 \\
3 & 4 & 12 \\
6 & 5 & 30 \\
2 & 6 & 12 \\
3 & 7 & 21 \\
4 & 8 & 32 \\
2 & 9 & 18 \\
1 & 10 & 10 \\
\hline
\end{tabular}




\begin{tabular}{ccc}
\hline 1 & 14 & 14 \\
3 & 15 & 45 \\
1 & 17 & 17 \\
1 & 20 & 20 \\
1 & 23 & 23 \\
48 & - & 293 \\
\hline
\end{tabular}

Fonte: Elaborada pelas autoras.

Os treinamentos realizados pelos multiplicadores foram avaliados pelos alunos, através de um questionário aplicado ao final das aulas. Este questionário foi respondido por 211 dos 293 usuários treinados e continha as seguintes perguntas:

1)Como você avalia o treinamento ministrado pelo aluno/colega multiplicador do programa?

2)Avalie o local de realização do treinamento.

3)Avalie o conteúdo repassado no treinamento.

4)Avalie a carga horária do treinamento.

5)Você já possuía algum conhecimento da base apresentada?

6)Você teria condições de repassar o conhecimento aprendido?

7)Apresente sugestões para os treinamentos ministrados no Programa Pró-Multiplicar.

Apesar dos alunos multiplicadores não terem formação específica na área de ciência da informação:

a) $98 \%$ dos alunos treinados os consideraram excelentes ou bons como instrutores;

b) $97 \%$ consideraram o local do treinamento excelente ou bom; e

c) $97 \%$ consideraram o conteúdo recebido excelente ou bom.

Observa-se, para essas três questões, a predominância da opção excelente, escolhida em cerca de $70 \%$ das respostas. Ainda é importante notar que, dos respondentes, $76 \%$ afirmaram que seriam capazes de retransmitir o treinamento recebido, o que demonstra a boa assimilação.

Registrou-se uma satisfação um pouco menor com a carga horária dos treinamentos (apenas 32\% a consideraram excelente) e com as respostas à questão de número 7 , qualitativa, que pedia sugestões para 0 Programa, o que confirmou o desejo dos alunos de que as aulas fossem mais longas e mais aprofundadas. As respostas também indicam a necessidade de maior divulgação do Portal e do conteúdo e uso de suas bases, já que $68 \%$ dos respondentes informaram não ter conhecimento prévio do conteúdo ministrado. 
A questão aberta (pergunta 7) mostrou, ainda, comentários que indicam a demanda por material didático de suporte para as aulas, de maior carga horária para exercícios práticos e até mesmo de inserção do treinamento na grade curricular, tornando-o obrigatório para os pósgraduandos, o que demonstra o interesse do público alvo pelo Portal e o valor que eles perceberam do treinamento recebido.

\section{Considerações finais}

Um dos pontos dignos de nota, em relação ao Programa PróMultiplicar na UFMG, foi a valorização do Programa pelos multiplicadores e seu entusiasmo com o conteúdo sendo ensinado, o que foi objeto de comentários pelos representantes das editoras e técnicos da CAPES, durante a realização do treinamento. Merece ser mencionado o interesse e esforço de um grupo de alunos da área de ciências biológicas, que foi além das exigências do programa, oferecendo, por sua própria iniciativa, para colegas e professores em sua unidade, um treinamento de 30 horas, em que utilizaram seu domínio da área de conhecimento para criar outros exercícios e demonstrações do uso e utilidade das bases de dados. Essa experiência vai ao encontro das expectativas da CAPES ao criar o Programa Pró-Multiplicar: "a participação dos bolsistas trará um elemento novo ao treinamento que se dará de colega para colega, destacando os conteúdos de interesse do pesquisador" (BRASIL, 2009). Sanler (2001, apud Del Fiaco, 2005) apresenta, também, observações sobre os benefícios do envolvimento maior do aluno no seu aprendizado:

Os métodos participativos levam o estudante a vivenciar situações propícias que possibilitam sua conversão em um ente ativo, criador, capaz de contribuir com o desenvolvimento do entorno social e sua própria autotransformação. Além de desenvolver talentos individuais, garante a formação de um alto grau de responsabilidade social e cidadã. (SANLER, 2001 apud DEL FIACO, 2005).

Destaca-se, também, a boa aceitação, pelos alunos multiplicadores, da metodologia de multiplicação desenvolvida, que gerou bons resultados em termos da carga cognitiva atribuída a cada multiplicador, da eficiência e da qualidade do treinamento.

O sucesso da metodologia é atestado pelo percentual mínimo ( $2 \%$ a $3 \%$ ) de respostas que consideravam apenas regular o desempenho dos instrutores e o conteúdo recebido; e pelo número, também mínimo, de reclamações manifestadas nas respostas qualitativas ao questionário de avaliação do curso.

Considera-se que teve fundamental importância para o sucesso do Programa a parceria entre os órgãos (Pró-Reitoria de Pós-Graduação, PróReitoria de Pesquisa, Biblioteca Universitária e Escola de Ciência da Informação), o apoio dos Pró-Reitores e a interação entre a professora (Diretora da Escola de Ciência da Informação) e bibliotecária (Diretora do 
Sistema de Bibliotecas da UFMG), Coordenadoras do Programa na UFMG (Figura 1).

Essa colaboração foi essencial para obtenção dos outros elementos que, também, foram fatores críticos para o sucesso do Programa, tais como a infraestrutura adequada e a colaboração dos programas de pósgraduação. Na segunda etapa de treinamento e no apoio aos alunos multiplicadores na preparação das aulas, os bibliotecários do Sistema de Bibliotecas colaboraram com aulas ministradas, completando lacunas de alunos multiplicadores para determinados conteúdos, além de apoiar o aluno multiplicador na preparação das aulas. O Setor de Apoio do Uso do Portal da Biblioteca Universitária manteve o controle das avaliações das aulas.

A metodologia adotada, em que se procurou garantir condições para que os multiplicadores se preparassem adequadamente e se sentissem confiantes quanto ao conteúdo a eles designado, foi fundamental. Na distribuição de encargos aos bolsistas multiplicadores, buscou-se, realisticamente, atribuir tarefas factíveis e compatíveis com os demais compromissos e demandas exigidas de um aluno de pós-graduação pelos seus cursos.

A experiência na UFMG também mostrou pontos que poderiam contribuir para melhoria, institucionalização, fortalecimento e mais fácil viabilização do Programa Pró-Multiplicar em ambientes diversos. Os alunos treinados manifestaram seu desejo de que as aulas fossem mais longas e aprofundadas e de maior carga horária para exercícios. Todas estas sugestões remetem à necessidade de apoio na criação de material didático para auxiliar os multiplicadores no seu próprio aprendizado e domínio do conteúdo que ministram, como, também, para uso nas aulas por eles ministradas.

Além disso, os DVDs com a gravação das aulas das editoras se mostraram extremamente desejáveis como material de apoio aos multiplicadores. Entretanto, a experiência mostrou que esse tipo de gravação tem características especiais, já que, muitas vezes, o instrutor fica de costas para a filmadora, o que prejudica a qualidade do áudio e as filmagens das telas do computador, mostradas através de projetores, não ficam legíveis na gravação.

A criação desse material didático, de forma profissional, de modo a garantir a uniformidade das aulas ministradas pelos multiplicadores, dentro do mesmo padrão de qualidade, exigiria um envolvimento e apoio de outros órgãos da instituição. Idealmente, a produção do material didático para uso no Programa seria centralizada, com a colaboração da CAPES, das editoras e das instituições envolvidas, evitando a duplicação de esforços em cada instituição em que o Programa Pró-Multiplicar fosse adotado, além de propiciar melhor qualidade dos materiais e uniformidade no ensino. Poder-se ia pensar em uma biblioteca digital, que organizasse e disponibilizasse esse material para as instituições que aderissem ao PróMultiplicar. Poder-se-ia, também, pensar mesmo em uma base de exercícios sobre o uso das bases de dados do Portal, para cada área do conhecimento. 
Finalmente, seria interessante estudar a possibilidade, também sugerida pelos alunos treinados pelo Programa, de inserção do treinamento no uso do Portal na grade curricular. Essa inserção poderia se dar de várias formas, sendo uma delas, por exemplo, o ensino do uso do Portal como um módulo dentro de uma disciplina introdutória ou de metodologia. A viabilização desta ideia dependeria de uma articulação entre bibliotecários, professores, colegiados e órgãos da universidade interessados na promoção da pesquisa e produtividade científica de sua comunidade.

Embora o grande esforço de organização tenha levado ao sucesso do Programa na UFMG, foi apresentado a CAPES o relatório da metodologia utilizada na instituição e sugestões colhidas durante o treinamento. Este relatório está disponível na Biblioteca Universitária.

\section{Referências}

BRASIL. Ministério da Educação. Portaria n. 144 de 20 de outubro de 2009. Aprova o Regulamento do Programa de Formação de Multiplicadores do Portal de Periódicos - Pró-Multiplicar. Diário Oficial da União, Brasília, DF, 22 out. 2009. Seção 1. p. 26-27. Disponível em: <http://www.periodicos.capes.gov.br/images/documents/ProMultiplicar PO144.pdf>. Acesso em: 4 jan. 2012.

COORDENAC̣ÃO DE APERFEICOAMENTO DE PESSOAL DE NÍVEL SUPERIOR (CAPES). Brasília, 2010. Possui acesso on-line aos periódicos com objetivo de disseminação da informação científica. Disponível em: <http://www.periodicos.capes.gov.br/>. Acesso em: 17 set. 2011.

COORDENAÇÃO DE APERFEIÇOAMENTO DE PESSOAL DE NÍVEL SUPERIOR - CAPES. Missão e objetivos. Brasília, 2011. Disponível em: < http://www.periodicos.capes.gov.br/?option=com pcontent\&view=pcontent\&alias=mi ssao-objetivos\&mn=69\&smn=74> . Acesso em: 23 out. 2012.

DEL FIACO, J. L. M. Métodos participativos: fundamentação teórica e um plano de aula para a disciplina teoria geral da administração, segundo o enfoque cultural e a teoria da atividade. Revista Administração, Santa Maria, v. 2, n. 2, p. 1-21, 2005. Disponível em:

$<$ http://revistas.unievangelica.com.br/index.php/administracao/article/viewFile/127/10 2>. Acesso em: 26 jan. 2012.

KURAMOTO, H. Acesso Livre + Portal de Periódicos da Capes = maior acesso à informação científica. 4 abr. 2008a. Disponível em:<http://kuramoto.blog.br/2008/04/04/acesso-livre-portal-deperiodicos-da-capes-maioracesso-a-informacao-cientifica/>. Acesso em: 27 nov. 2011.

SANLER, V. C. Métodos Participativos. Havana: CEPES, 2001. 